\title{
Integration and Development of National Traditional Sports and Community Sports from the Perspective of Harmony
}

\author{
LIUChuan-Qin ${ }^{1}$, ZhangHzi-Zhi ${ }^{2}$ and ZhangYou-Ming ${ }^{3}$ \\ ${ }^{1,3)}$ Institute of sports science, Mudanjiang Normal College, Mudanjiang, Heilongjiang, China \\ 2) Physical Education College of Harbin University of Commerce, Harbin, Heilongjiang, China
}

\begin{abstract}
- the national harmony is the foundation of constructing harmonious society, national traditional sports is rich in the content of building a harmonious society, the fusion and development of national traditional sports and community sports is an effective way to promote national harmony. Combined with the national traditional sports and the community sports, not only can enrich the community sports content, improve the community residents to participate in community sports interest, promote the development of community sports, but also stimulate the innovation to the inheritance and development of traditional national sports. At the same time, to enhance the cohesion of the Chinese nation, to promote national cooperation, promote national harmony, so as to promote the building of a harmonious society.
\end{abstract}

Keywords — national traditional sports, community sports development, fusion

\section{和谐视角下民族传统体育与社区体育的融合与发展}

\author{
刘传勤 ${ }^{1}$ 张海志 $^{2}$ 张有明 $^{3}$ \\ ${ }^{1,3)}$ 牡丹江师范学院体育科学学院，牡丹江，黑龙江，中国 \\ 2) 哈尔滨商业大学体育学院, 哈尔滨, 黑龙江, 中国
}

摘 要 民族和谐是构建和谐社会的基础, 丰富民族传统体育是和谐社会建设的内容, 民族传统体育与社区体育的融合与发展是 促进民族和谐的有效途径。民族传统体育与社区体育的结合，不仅可以丰富社区体育内容，提高社区居民参与社区体育的兴趣，促进 社区体育的发展, 而且还能带动民族传统体育的继续传承与发展创新。同时，有利于增强民族凝聚力，有利于促进民族互助，有利于 促进民族和谐, 从而促进和谐社会的建设。

关键词 民族传统体育，社区体育，融合，发展

社区体育作为全民健身活动的基本载体，它是以体育 健身、娱乐和休闲为主, 其目的主要是改善社区广大居民 群众的生活质量, 提高国民身心健康水准, 为国民综合素 质的提高服务。社区体育，不仅确定了“健身”的根本目的， 而且明确了“社区居民”为实施对象。要切实做到最广泛的 居民参与和全方位的体育普及, 除了要有优越的制度和发 达的经济基础外, 更要求活动内容本身具有很强的大众吸 引力和凝聚力。这就要求活动内容丰富, 形式多样, 它应 该拥有尽可能多的、积极的、健康的体育活动项目, 使不 同年龄、不同职业、不同体质的人都能选择到适合自己的
活动内容, 同时这些活动内容还应该具有深沉的文化底蕴, 使之具有鲜明的民族特色和风格。从而使社区不同层次的 居民参与到社区体育活动中来, 使社区体育活动的参与面 更广、更有效。而民族传统体育是中华民族在几千年繁衍 生息的发展历史进程中, 以自己的聪明才智创造并流传下 来的民族文化瑰宝。它兼容了各个历史阶段的优秀体育成 果, 融会了各个民族丰富的民族文化, 并与传统哲学, 中 医理论等适当地结合, 形成了独特的体育思想和健身理论。 民族传统体育内容丰富, 形式多样, 具有强身健体、文化 传承之效, 且具有很深的文化内涵, 具有民族间联系和交 
流的桥梁与纽带作用, 是联系民族感情、加强民族团结和 提高民族凝聚力的一个重要手段。因此, 民族传统体育作 为社区体育文化资源, 不仅有利于广泛开展大众健身活动, 而且有利于中华民族文化的丰富和发展、有利于社会主义 和谐社会建设。

\section{1. 民族传统体育的特性}

我国民族传统体育是指在中华历史上一个或多个民族 内流传或继承的体育活动的总称。主要是指我国各民族传 统的祛病、健身、习武和娱乐活动项目。民族传统体育是 在特定的地理环境、社会生产方式、历史条件、文化水平 以及宗教、民俗等因素的作用下形成的。我国少数民族传 统体育反映人民对美好生活、崇高理想的追求，它与本民 族的劳动生产、民间艺术、科学文化、道德风尚、风土人 情, 乃至除暴安良、保家卫国紧密结合, 形成了以下鲜明 的特点。

\section{1 民族传统体育内容丰富}

中华民族传统体育是中华民族宝贵的文化遗产，民族 传统体育项目繁多, 内容丰富, 有许多优秀的传统体育项 目, 不仅有很强的健身价值, 而且还有很高的艺术价值和 丰富的娱乐、教育功能。为了把这些民族体育瑰宝, 非物 质文化遗产得以传承和发扬光大, 挖掘整理出了 1000 多个 体育项目。比如蒙古族被称为 “男儿三项游艺”的摔跤、赛 马、射箭; 回族的踢珴、拔河; 藏族的赛牦牛; 苗族的荡 秋千、划龙舟; 壮族由青年男女表达爱情转变为对抗性比 赛项目的“投绣球”; 朝鲜族的跳板; 满族的滑冰; 侗族的 骑木马 (踩高脚); 瑶族的打陀螺; 高山族的放风筝; 柯尔克 孜族的“追姑娘”; 布朗族的藤球等等。而龙舟竞渡、风筝、 秧歌、围棋、气功、太极拳等, 则是汉族与少数民族都共 同喜爱的传统体育项目。

\section{2 民族传统体育具有健身性和娱乐性}

健身强体是体育的本质功能, 早在原始社会, 人们就 已认识到人体运动对身体健康的促进作用, 从“流水不腐, 户枢不冨” 的比喻中也可看出古人对运动价值的认识。几乎 每项传统体育都具有明显的强健身心的功能, 有些项目甚 至既无竞技性, 也无娱乐性可言, 但却具有良好的健身功 能, 如华佗的五离戏等医疗保健功、导引养生术。

娱乐性是中国民族传统体育的最大特点之一，欢悦的 身体活动在远古时代就是人类文化生活中不可缺少的重要 内容, 传统体育文体合一的特点使运动者和观赏者得以愉 悦身心, 陶冶性情, 调节情绪, 满足精神文化需要。在各 少数民族的传统节日中, 众多载歌载舞、节奏明快、活泼
风趣的体育娱乐活动成为主要内容。甚至在今天的全国少 数民族传统体育运动会上, 以娱乐性见长的非竞赛项目仍 大大多于竞赛项目。如彝族的“阿细跳月”、傣族的“象脚 鼓”、纳西族的“东巴跳”、苗族的“跳芦笙”、“鼓舞”、黎族 的“跳竹竿”等等(饶远, 1992), 都是融健身性、娱乐性、趣味 性、艺术性为一体的体育娱乐项目。

\section{3 民族传统体育具有经济性和实效性}

民族传统体育项目，几乎都是“土生土长”的健身运动 形式, “是各民族长期生活、生产实践的结晶”, 虽然它经 过长期的发展、演变和丰富, 但它的基本特征和健身功能 还相对稳定, 而且简便易行, 老少皆宜, 功效显著, 这使 得它极易被群众认知、接受和参与, 形成了相对稳定的群 众基础, 自然而然地也就成了群众生活的一部分。民族传 统体育是从自给自足的自然经济的土壤中产生和发展起来 的, 这就决定了它的功能和经济的相对游离, 因而, 大多 数民族传统体育项目的开展对场地、设施、器材经费和活 动的组织都要求不高。

\section{4 民族传统体育具有交往功能}

一个民族作为社会的一个群体, 它有同一信仰和文化, 为了让民族内人民紧密地联系在一起, 追求和增强共同的 群体意识, 就必须寻求一种良好的手段, 而民族传统体育 就是这样一个有效手段。随着人类的进步和时代的发展, 这种手段的作用尤为明显。中华民族是一个由 56 个民族组 成的大家庭, 其中占总人口 $92 \%$ 的是汉族, 也有人口仅 1000 人左右的门巴族和珞巴族。新中国成立后, 党和政府高度 重视民族工作, 分别在天津、内蒙古、新疆、广西、云南 和北京(西藏)、宁夏举办了 7 届全国少数民族传统体育运 动会, 设置的项目和参赛的人数不断增多, 运动会的规模 和影响逐届扩大。民族传统体育作为一种媒介, 发挥了民 族间联系和交流的桥梁与纽带作用, 成为联系民族感情、 加强民族团结和提高民族凝聚力的一个重要手段。

\section{2. 民族传统体育与社区体育发展}

民族传统体育与社区体育融合与发展, 不仅能继承民 族传统文化, 使其不断完善与发展, 而且还能为社区体育 的发展增添活力, 丰富社区的体育内容, 促进社区体育的 发展。同时还有利于和谐民族关系, 有利于增强民族自信 心和民族凝聚力, 有利于和谐社会的建设。

\section{1 有利于民族传统体育的传承和发展}

民族传统体育与社区体育相结合, 有利于民族传统体 育的继承和发展。把那些历史悠久娱乐性、健身性、观赏 
性强的少数民族特有体育项目融入社区体育中, 如：踢毽 球、扭秧歌、舞狮子、追姑娘、太极拳及其他形象、简单、 易学的传统体育项目等。这些项目以其本身的特性, 必将 吸引更多的社区居民参加练习, 因而对民族传统体育的普 及和推广将起到积极的促进作用。此外, 通过练习民族传 统体育项目, 可使社区居民在练习的过程中逐步认识到民 族传统体育的悠久历史和丰富多彩的内容, 认识到民族传 统体育文化的独特内涵和在健身中所起到的独特作用。而 且还可以根据需要对民族传统文化加以改造, 注入新的内 容, 使其不断完善与发展, 实现这些项目的长期发展和继 续流传。

\section{2 丰富社区体育内容, 促进社区体育的发展}

民族传统体育与社区体育的融合, 可以丰富社区体育 的内容, 促进社区体育的发展。民族传统体育具有内容丰 富、形式多样、简单易学、老少皆宜的特点。如苗族的猴 儿鼓、舞龙、舞狮、武术, 土家族的摔跤、高脚马、秋千、 踢珴子, 侗族的抢花炮、踩芦笙, 壮族的秋千、抢花炮、 打陀螺等。这些民族传统体育项目本是当地居民在长期社 会生活中创造的，作为一种健身方式之一，这些民族传统 体育非常符合现代社区体育活动中所提倡的休闲性、观赏 性、娱乐性、趣味性、简便性的要求。把这些具有健身性、 娱乐性和适宜性等特点的民族传统体育融入社区，不仅可 以极大地丰富社区体育的内容, 为社区居民选择适合自己 活动的项目和形式提供更广阔的空间，大大提高社区居民 参与社区体育的兴趣, 而且会使社区体育活动的参与面更 广、更有效。这必将有利于促进社区体育的可持续发展。

\section{3 弥补社区体育现实的不足}

民族传统体育与社区体育的融合, 可以弥补社区体育 现实的不足。我国现阶段, 影响社区体育实施和发展的最 大因素是, 除了受到管理职责不明、体育活动需求不足等 条件制约外, 资源贵乏更是突出因素。我国现阶段经济还 不很发达, 社区的资金更是极为短缺。因此, 把那些不仅 使人们喜闻乐见，能全身心地投入，而且投入资金少、健 身效果明显, 娱乐性强、又不受活动场地、设施限制的具 有很强生活气息的民族传统体育项目融入到社区体育中。 可以解决目前发展社区体育所面临的资金不足问题。如风 筝、踢建球、扭秧歌等不需要花费大成本来购买硬件设施 器材, 又广为人民群众所喜欢。

\section{4 有利于和谐民族关系}

民族传统体育与社区体育的融合, 有利于和谐民族关
系。一个民族为了自身利益和求得自身的发展, 总是需要 和其他民族发生联系, 进行交流, 取长补短。民族传统体 育作为一种媒介, 发挥着民族间联系和交流的桥梁与纽带 作用。各民族借体育盛会欢聚一堂, 既振奋民族的精神, 也将各族人民紧密地联系在一起。民族传统体育作为联系 民族感情、加强民族团结和提高民族凝聚力的一个重要手 段, 将民族体育融入社区体育, 弘扬民族传统体育, 对于 和谐民族关系将起着重要作用。

\section{5 有利于民族互助}

各民族共同团结奋斗、共同繁荣发展是通过互助实现 的。互助是民族关系充满活力的表现, 其特点是各民族之 间的联系日益密切和相互依存。汉族离不开少数民族, 少 数民族离不开汉族, 少数民族之间也相互不可分割。我国 各民族之间互助、平等、团结是共同繁荣发展的基础。各 民族之间的互助, 保持文化多样化、生态多样性、资源多 样性是国家统一, 维护全局利益和构建和谐社会不可或缺 的。

少数民族传统体育活动如舞龙、舞狮、踩高跷、龙舟 竞渡、斗牛、拔河、赛马等活动, 参加比赛者除了进行激 烈的竞争外, 集体内各成员相互配合和协作, 往往是取得 胜利的关键。即使旁观者也都难以作为局外人, 他们自觉 或不自觉地进入角色, 为自己集体欢呼鼓劲或沮丧惋惜。 这种将个人荣誉和集体荣誉融为一体的少数民族传统体育 活动, 对培养民族团结精神起到了积极的作用。因此, 民 族传统体育融入社区体育有利于互动交流、激发创造力, 激发全社会创造活力, 促进社区和谐发展、社会文明进步。

\section{6 有利于增强民族凝聚力}

民族传统体育是民族文化的一个重要形式, 它凝结了 各民族人民的智慧, 是各族人民在历史发展过程中创造、 发展起来的。它密切联系着各民族人民的生产、生活实践, 是民族文化体系中最具有代表性的文化特质, 它不仅统一 着社会成员的行为方式, 更重要的是维系着群体和民族的 文化心理, 加强了人民内部的凝聚力, 因而, 民族传统体 育具有作为活动内容所必需的文化整合力和文化凝聚力。 在社区体育活动中推广民族传统体育, 不仅有利于弘扬民 族传统文化, 激发爱国主义热情, 增强民族自尊心和自豪 感, 吸引人们积极主动地参加, 壮大群众体育队伍, 也有 利于形成具有中国特色的社区体育体系, 对社会主义精神 文明建设做出贡献。

\section{3. 结束语}

随着我国经济的发展和社区居民生活水平的提高, 我 
国的社区体育有了较大的发展。我们要结合社区实际, 努 力探索适合社区居民特点的体育活动方式。民族传统体育 具有独特的特点、功能和价值, 以及在社区开展的优势, 决定了它必将成为具有中国特色的社区体育的主要内容。 民族传统体育与社区体育的结合, 不仅能满足社区居民健 身的需求，丰富居民的业余文化生活、促进居民的交往、 增强民族自信心和凝聚力, 而且, 在推动社区体育快速发 展的同时, 对民族传统体育文化的继承和发展也起到良好 的促进作用。所以，加强民族传统体育与社区体育的结合， 促使其互动式发展, 对和谐社会的构建有着巨大的推动作 用。

\section{参考文献(References)}

[1] Li Hongjiang. China national sports introduction. Beijing: China books publishing house, 2000

[2] Xiao Linpeng. social sports management in Beijing: Beijing Sport University press, 2005

[3] Lu Pingsheng, Yang Lansheng. Research on. of national traditional sports in Gansu: Gansu Education Press, 2002

[4] Zhao Li, Luo. Community sports theory and practice. Beijing: Beijing Sport University press, 2001

[5] Fan Bingyou. The community sports theory. Beijing: Beijing Sport University press, 2002
[6] Yu Lin. The feasibility study of the. national sportsinto the community sports development of Zhejiang sports science, 2003, (6): 9-11

[7] Ni by. The development of the Chinese traditional sportsand. sports science, 2004 (11): 54- 61

[8] Liu Shaoying, Tian motherland, et al. Hunan Hubei Chongqing Guizhou border area national minority tradition sports project analysis and research. Journal of Beijing Sport University, 2002, (2): 152-154

[9] Lv Zhengjiang. The characteristics and development trend of national traditional sports and. sports, 2000, (6):38 - 39.7

[10] Tian Zuguo, Zhang Jianxin. The National Traditional Sports in the city community culture construction in value and practice. Anhui sports science and technology, 2005, (3): 73- 75

[11] Liu Aiping, national traditional sports and the construction of harmonious society. Journal of physical education, 2007.6

[12] Yang Jian, Wang Yonggan. The national traditional sports and community sports. Langfang Teacher's College journal, 2006, (4): 90-92

[13] Wang Jiazhong, Xu Xinrong. Research on the contemporary community. the National Traditional Sports Journal of Anhui Institute of Education, 2007, (3) 